\title{
Mechanical and Flame-Retardant Properties of Exoxy Epikote 240/Epoxidized Linseed Oil Composites Using Fiber-Glass
}

\author{
NGUYEN TUAN ANH* \\ RECEIVED ON 10.03.2019, ACCEPTED ON 13.06.2019
}

\begin{abstract}
Flammability of polymer composite appears to be one of the greatest threats and hence limits its advanced applications. Polymer composite materials can be designed to obtain wide ranges of properties in comparison with traditional materials. However, almost common polymers include the intrinsic flammability, restricting their applications in spite of their flexibility and performance efficiency. In this study, a material based on epoxy Epikote 240 resin $90 \mathrm{phr}$ and epoxidized linseed oil $10 \mathrm{phr}$ was prepared. In order to improve the material's flame retardancy ability but maintain its mechanical strength, the mixture of flame retardants including $9 \mathrm{phr}$ antimony trioxide and $11 \mathrm{phr}$ chlorinated paraffins along with amin compounds as a curing agent were added into the material. In addition, $\mathrm{E}$-glass woven fabric (E $600 \mathrm{~g} / \mathrm{m} 2$ ) was used to improve mechanical strength of the material. As a result, the material was considered as the flame- retardant material with LOI index to be $30.3 \%$.
\end{abstract}

Key Words: Flame Retardant, Epoxy Resin, Antimony Trioxide, Epoxidized Linseed Oil, Chlorinated Paraffins. E-glass.

\section{BACKGROUND}

$\square$

LO (Epoxidized Linseed Oil) has been one of plasticizers and stabilizers for plastic production including PVC (Polyvinyl Chloride) and polymers with a purpose of keeping them flexible as well as ductile. ELO provides stability, heat and light. It was used instead of DOP (Dioctyl Phthalate) because its biodegradable is better than common phthalate plasticizer. In recent years, under pressure of environmental pollution, bio-composite materials have increasingly attracted attention of researchers. In 2010, ESO (Epoxidized Soybean Oil) was used to replace a part of epoxy diane background based on bisphenol A in composite materials reinforced with glass beads. Mechanical properties of this type of plastic background with $60 \%$ wt of ESO were equivalent to epoxy diane background [1-2]. Takashi Tsujimoto at et studied to create green nanocomposite based on ESO reinforced nanosilica $30 \mathrm{~nm}$ in size $(95,5 \% \mathrm{wt})$. Hardness and Young's modulus were significantly increased by using silane adhesive than no silane $\left(9-22 \mathrm{~N} / \mathrm{nm}^{2}\right.$ and from 210-620 $\mathrm{MPa})$. ESO was also used to increase the impact resistance of unsaturated polyester (PEKN): when no ESO, the impact resistance of PEKN was $26 \mathrm{~J} / \mathrm{m}$, it increased $38 \%$ with $10 \%$ wt of ESO. When amount of ESO increased $20 \%$, the impact resistance was $77 \%$. However, the tensile strength of PEKN/ESO with ratio of $80 / 20$ decreased $5 \%$ compared to pure PEKN resin [3-4]. Epoxy resins are known to have high mechanical strength but have brittle disadvantages, low fire resistance, and non biodegradability. Therefore, 
modifying epoxy resin to have good mechanical properties and high fire resistance has been researched by many [57]. In addition, to enhance the mechanical properties epoxy materials are reinforced by nano additives and glass fiber combined Kevlar fiber [8-10]. In this study, we studied the flammability and mechanical properties of composites with epoxy/ELO background and presence of flame retardants $\mathrm{Sb}_{2} \mathrm{O}_{3}$ and chlorinated paraffins.

\section{EXPERIMENTAL SETUP}

\subsection{Raw Materials and Chemicals}

Epoxy Epikote 240 (Epoxy E 240) resin of Dow Chemicals (USA) with epoxy group content of $24,6 \%$, Mw: 5100$5400 \mathrm{mmol} / \mathrm{kg}$; density: 1,12, viscosity at 250C: 007-1.1Pa.s. DETA (Diethylenetriamine) of Dow Chemincals (USA), density 0.95 , boiling point $207^{\circ} \mathrm{C}, \mathrm{Mw}: 103$. Chlorinated paraffin (S52) (China), Maximum amount of chlorine included in chlorinated paraffin is $52 \%$. Antimony trioxide (China), Content of antimony trioxide $>99.0 \%$, some important properties of antimony trioxide are as follows: it is a white powder, melting point of $656^{\circ} \mathrm{C}$, specific gravity of 5,7, the amount of included metallic antimony of approximately $83 \%$. Commercial powder of epoxidized linseed oil was collected from Akcros Chemicals Limited with the size of $1.5 \mu$. Appearance: Liquid Solidifies at low temperatures Colour: Light (or pale) Yellow - Water-white Solubility: Insoluble in water viscosity at $25^{\circ} \mathrm{C}: 800 \mathrm{cSt}$, with epoxy group content of $22,89 \%$
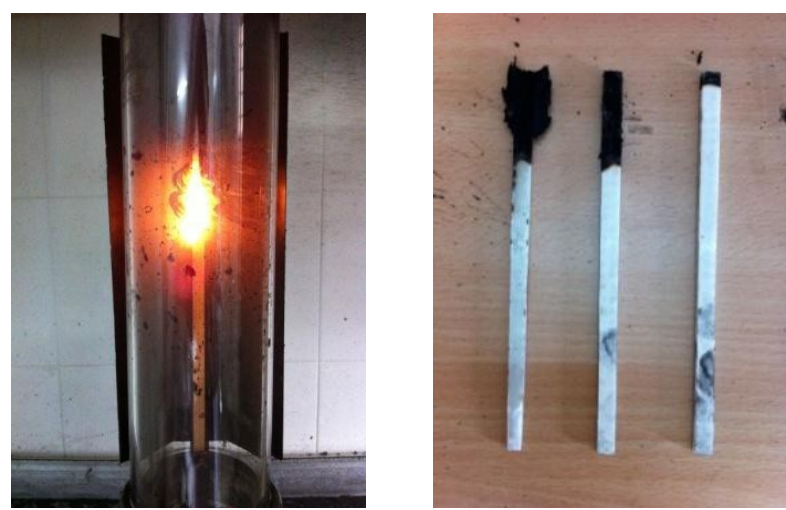

FIG. 1(A). IMAGE OF FIRE RETARDANT TEST ACCORDING TO LOI

\subsection{Research Methods Used}

The fire retardancy of epoxy/epoxidized linseed oil/Sb2O3/ chlorinated paraffins mixture was determined by limiting oxygen index (LOI) method with ASTM 2863 standard using LOI analyzer (Dynisco) in oxygen-nitrogen atmosphere. The LOI values show the minimum level of oxygen which is needed for combustion process carried out by a Bunsen burner. In these experiments, the samples were combusted vertically. The level of oxygen in the atmosphere was increased steadily until the flame was extinguished but the burning time is 3 minutes or burned part of the sample reaches $5 \mathrm{~cm}$ (Fig. 1(a)).

The UL-94HB rating was tested according to the UL-94HB (ASTMD635-12) with sheet dimensions of $125 \pm 5 \mathrm{~mm}$ long by $13.0 \pm 0.5 \mathrm{~mm}$ wide, and provided in the minimum thickness and $3.0(-0.0+0.2) \mathrm{mm}$ thick (Fig. 1(b)).

FE-SEM method using a S-4800 scanning electron microscopewere was used to observe dispersion of structure of the samples cut into small pieces and coated with gold before measuring.

Measurement method (Tensile strength, Flexural strength, Compressive strength) and fabrication pattern are shown in Fig. 2(b) and Fig. 3.

Tensile strength was determined according to ISO 1781993 standard in INSTRON (USA) equipment with crosshead spead $2 \mathrm{~mm} / \mathrm{min}$, temperature $25^{\circ} \mathrm{C}$ and humidity $75 \%$.

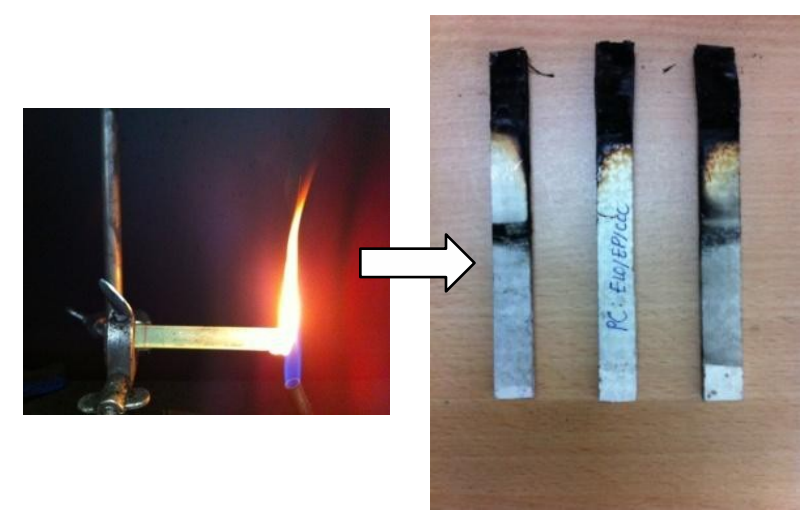

FIG. 1(B).UL $94 H B(B)$

Mehran University Research Journal of Engineering \& Technology, Volume 39, No. 1, January, 2020 [p-ISSN: 0254-7821, e-ISSN: 2413-7219] 
Flexural strength was determined according to ISO 1781993 standard in INSTRON (USA) equipment with

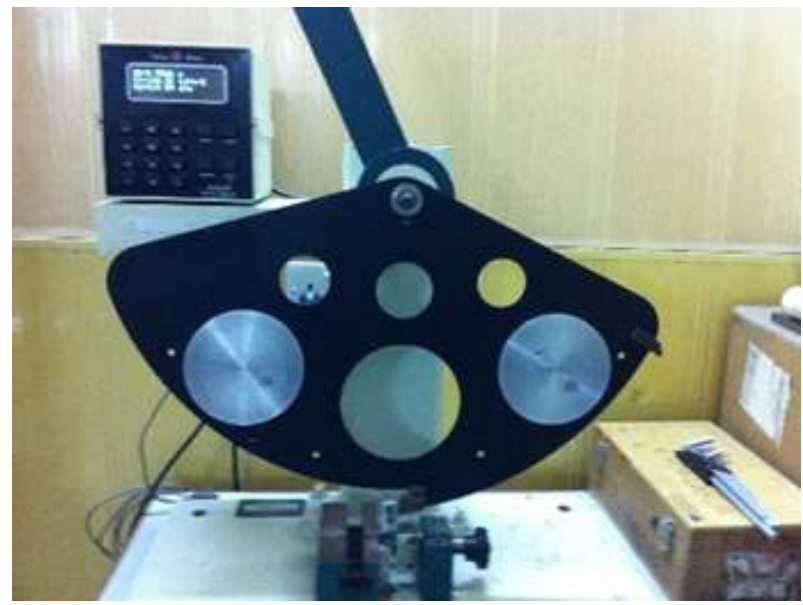

FIG. 2(A). IZOD IMPACT TESTERS

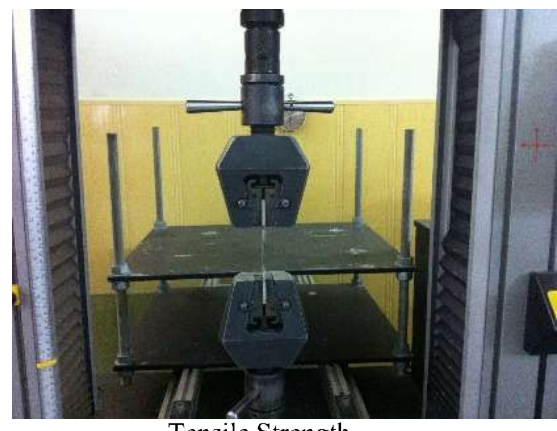

Tensile Strength
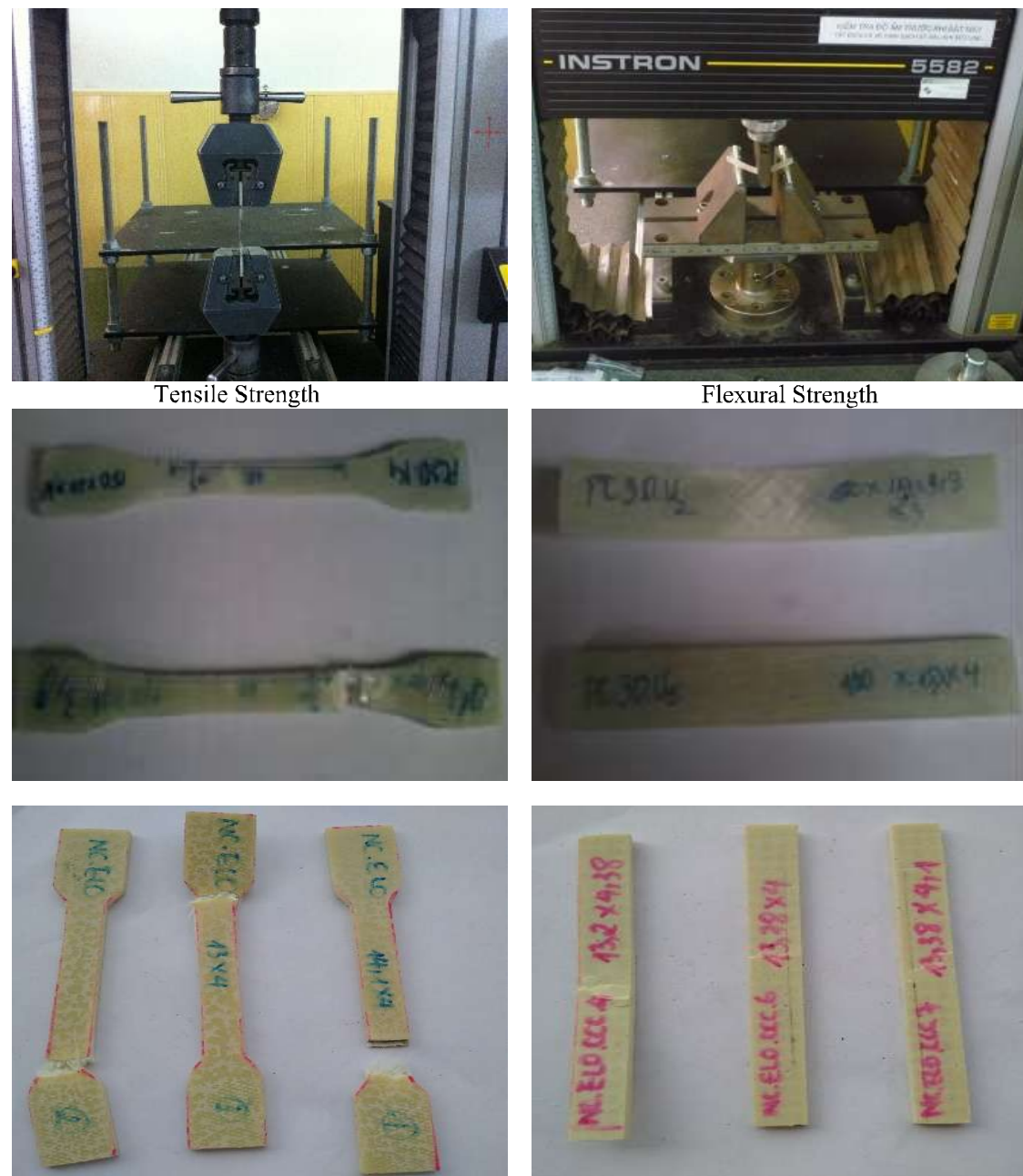

Flexural Strength
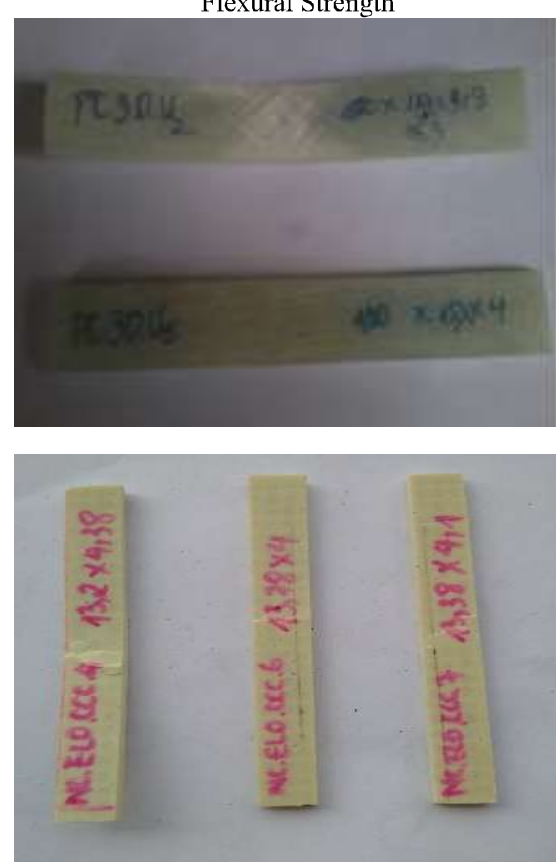

FIG. 3. MECHANICAL STRENGTH MEASUREMENT $75 \%$. crosshead spead $2 \mathrm{~mm} / \mathrm{min}$, temperature $25^{\circ} \mathrm{C}$ and humidity

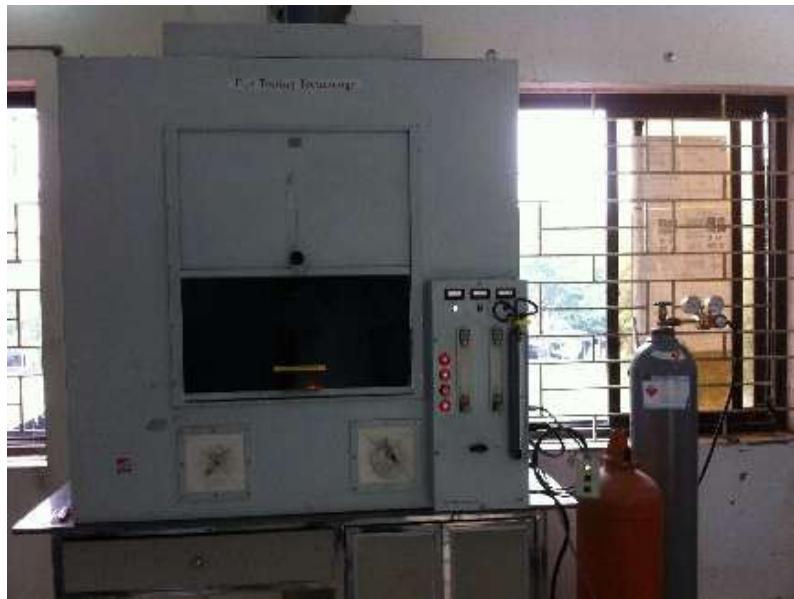

FIG. 2(B). UL-94HB RATING (B)

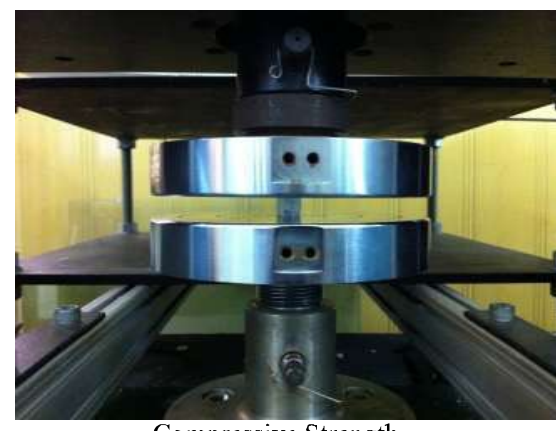

Compressive Strength
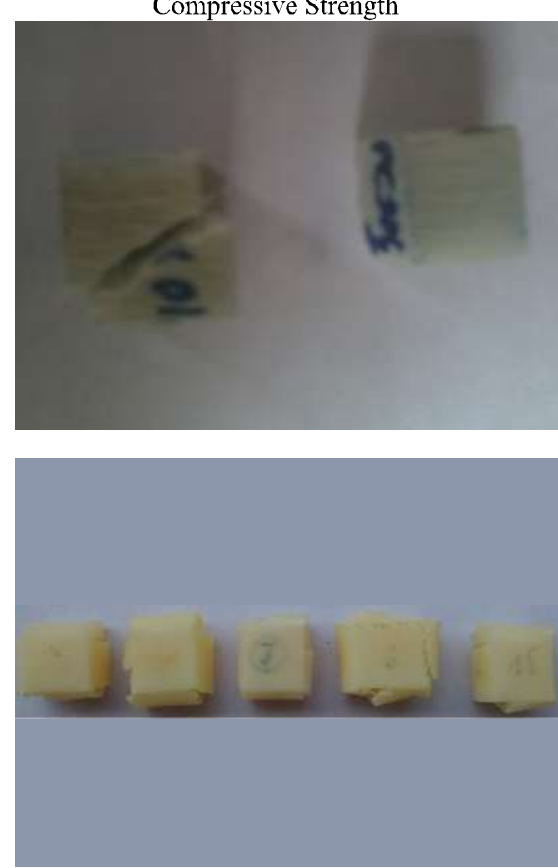

ENT

.

Mehran University Research Journal of Engineering \& Technology, Volume 39, No. 1, January, 2020 [p-ISSN: 0254-7821, e-ISSN: 2413-7219] 
Compressive strength was determined according to ISO 178-1993 standard in INSTRON (USA).

Izod Impact Strength was determined according to ASTM D265 satndard in Tinius Olsen (USA). Specimen size: The standard specimen for ASTM is $64 \times 12.7 \times 3.2 \mathrm{~mm}\left(2 \frac{1}{2} \mathrm{x} \frac{1}{2} 2 \mathrm{x} 1 /\right.$ 8 inch). Izod Sample Geometry: $2 \mathrm{~mm}$. Model manufacturing as shown in Fig. 4 and image measuring equipment Fig. 2(A).

\subsection{Preparation of Epoxy/Epoxidised Linseed Oil/Sb2O3/Chlorinated Paraf?ns Mixture}

Specimen Preparations Blend Epoxy Epitoke 240/ELO: Epoxy Epikote 240 resin was mixed with Epoxidized linseed (90/10 phr) in $250 \mathrm{ml}$ round bottomed three neck flask, mixture was stirred 1500 rpmin 1 hour and it had a thermal stability at $80^{\circ} \mathrm{C}$. The bubble free mixture was put into a mold and cured at room temperature within $24 \mathrm{~h}$, then dried within $3 \mathrm{~h}$ at $80^{\circ} \mathrm{C}$. After 7 days, mixture was analyzed and mechanical properties (EO-Epoxy/ELO) were measured. Aluminum mould with a realease agent (Wax 8.0, USA) was used to hardern the blend and make it esier for removing product to outside.

Specimen Preparations Blend Epoxy Epitoke 240/ELO/ $\mathrm{Sb}_{2} \mathrm{O}_{3} /$ Chlorinated paraffins: 55g Epoxy Epikote 240 resin was mixed with 2,894 Epoxidized linseed (EP/ELO $=90 / 10$ phr), $4.95 \mathrm{~g} \mathrm{Sb}_{2} \mathrm{O}_{3}$ and $6.05 \mathrm{~g}$ Chlorinated paraffins $\left(\mathrm{Sb}_{2} \mathrm{O}_{3} /\right.$ Chlorinated paraffins $=9 / 11 \mathrm{wt} \%$ ) follow other ratios in $250 \mathrm{ml}$ round bottomed three neck flask, mixture was stirred 1500 round/minute in 3 hour and it had a thermal stability

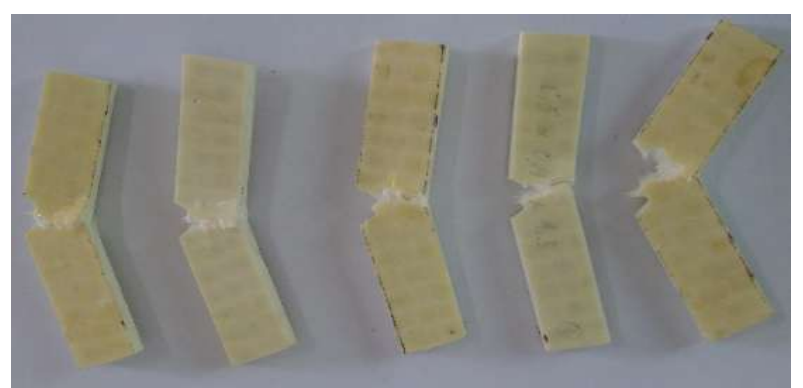

at $80^{\circ} \mathrm{C}$. Homogeneous mixture was cured by DETA at room temperature in 24 hours, then it was dried at $80^{\circ} \mathrm{C}$ in 3 hours. After 7 days, mixture was analyzed and measured mechanical properties (EAP-Epoxy/ Sb2O3 9phr/ Chlorinated paraffins 9phr) (See Fig. 5.).

The sheets of Epoxy/ELO/Sb2O3/Chlorinated paraffins/ glass fibers $\mathrm{PC}$ were prepared by the manual methods after dispersing $\mathrm{Sb}_{2} \mathrm{O}_{3}$ and chlorinated paraffins into epoxy resin: E-glass/epoxy composites were made by hand lay-up method. Firstly, epoxy resin modified with $\mathrm{ELO} / \mathrm{Sb}_{2} \mathrm{O}_{3}$ /Chlorinated paraffins was spread uniformly by a paint brush on each E-glass woven fabric layer. Secondly, a panel including 9 layers stacked together was formed. Thirdly, the panel was dried at room temperature within $24 \mathrm{~h}$. Finally, the panel was dried at $80^{\circ} \mathrm{C}$ within $3 \mathrm{~h}$. The final thickness of the panel was measured to be $4 \mathrm{~mm}$ (Fig. 6.).

\section{RESULTS AND DISCUSSION}

\subsection{Effects of Process Variables on Morphological Structure of Materials}

Morphological structure of materials was studied by scanning electron microscope. Fig. 7 and Fig. 8 show SEM images of several typical material samples. Realized that: in EO, ESO particles are uniformly distributed in epoxy resin background with about $1-5 \mu \mathrm{m}$ in size. The compatibility between ELO and epoxy resin is high due to increased level of dispersion, created homogeneous mixture before curing. In formation process of cross- link had phase separating created ELO particles acted as filler.

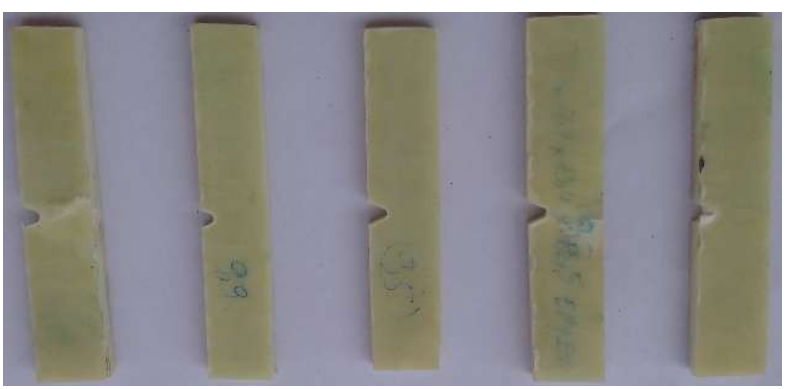

FIG. 4. MECHANICAL STRENGTH MEASUREMENT

Mehran University Research Journal of Engineering \& Technology, Volume 39, No. 1, January, 2020 [p-ISSN: 0254-7821, e-ISSN: 2413-7219] 
They increased mechanical properties of epoxy background materials.

On the other hand, the FE-SEM image of Fig.8 shows that $\mathrm{Sb}_{2} \mathrm{O}_{3}$ and chlorinated paraffin are fairly uniformly distributed. Chlorinated paraffin is distributed in a smaller size in epoxy resin that is clearly visible. The chlorinated paraffin drops are low molecular organic compounds in liquid form that are mixed with Epoxy E240 distributed in

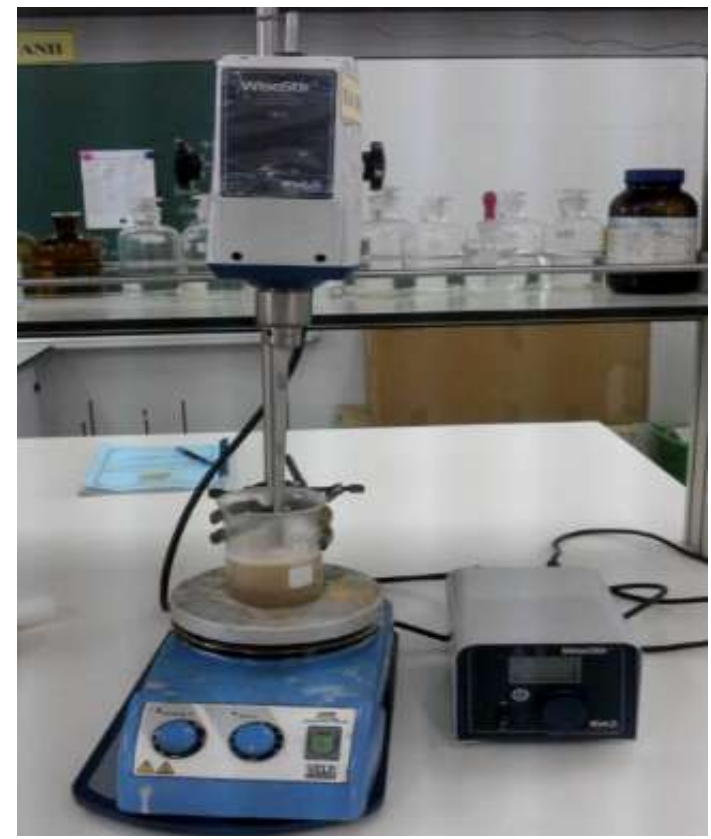

FIG. 5. MANUFACTURING SET UP OF EPOXY COMPOSITE: EPOXY EPIKOTE 240/ELO/ $\mathrm{SB}_{2} \mathrm{O}_{3} /$ CHLORINATED PARAFFINS
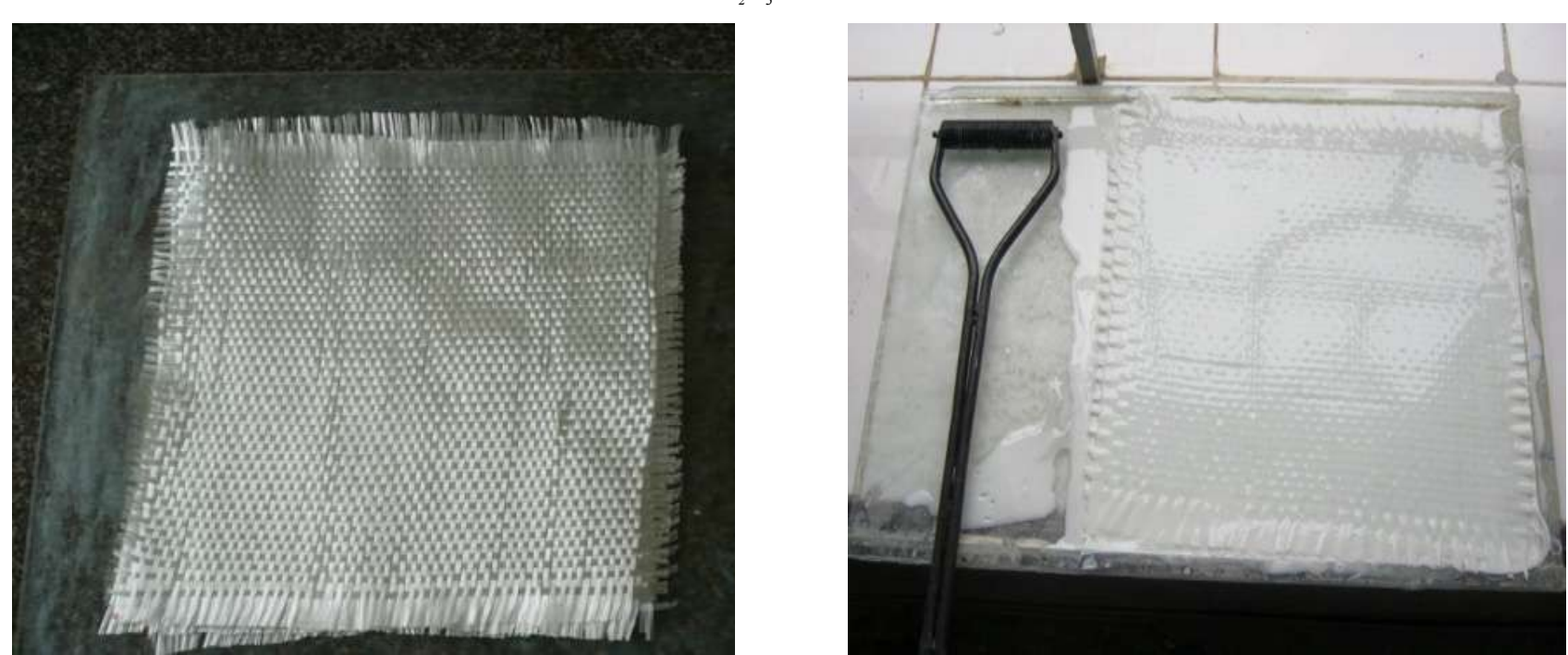

FIG. 6. FIBER GLASS/EPOXY/ELO $\mathrm{SB}_{2} \mathrm{O}_{3}$ /CHLORINATED PARAFFINS/ COMPOSITES

Mehran University Research Journal of Engineering \& Technology, Volume 39, No. 1, January, 2020 [p-ISSN: 0254-7821, e-ISSN: 2413-7219]

granular form in epoxy E240 background phase to create a plasticizing effect.

Therefore, the fire retardation is improved, while the mechanical properties remain high. This result is consistent with the results of determining the mechanical properties and fire retardation mentioned above. Antimony oxide particles were dispersed fairly well and wetted well, no holes appeared and $\mathrm{Sb}_{2} \mathrm{O}_{3}$ particles

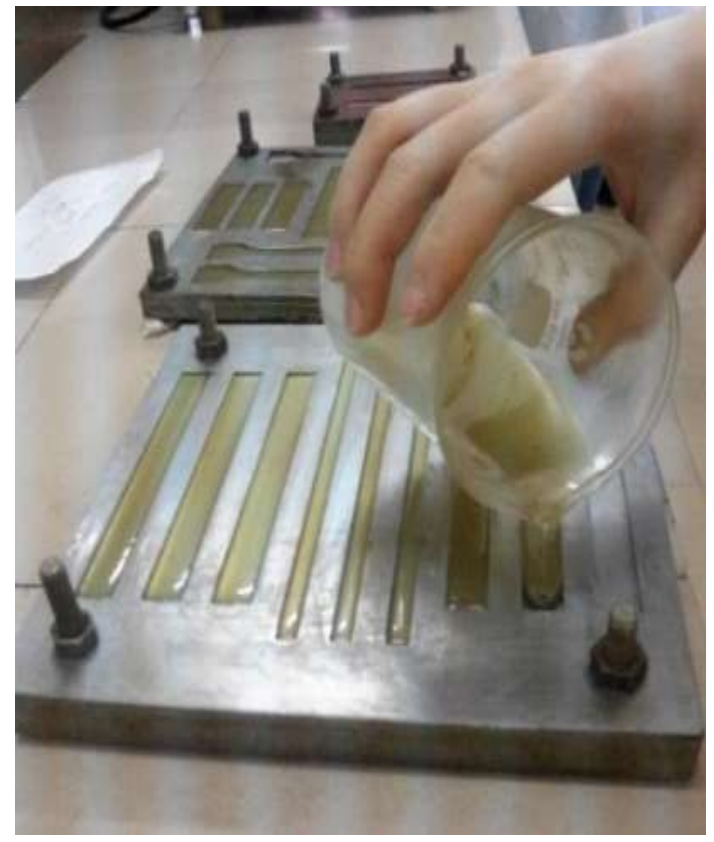


adhered well to E240 epoxy, the broken surface of the material is smooth.

The size and extent of distribution of the ELO particles dispersed in epoxy is one of the important factors, if appropriate size would improve the material properties. If the size is appropriate, it will improve the properties of the material. In this case, the ELO is formed in epoxy resin in the form of spherical particles elastic as rubber, with the appropriate size and level of distribution, hence the bending strength and impact strength Izod increased compared to E 240 epoxy resin (Fig. 8).
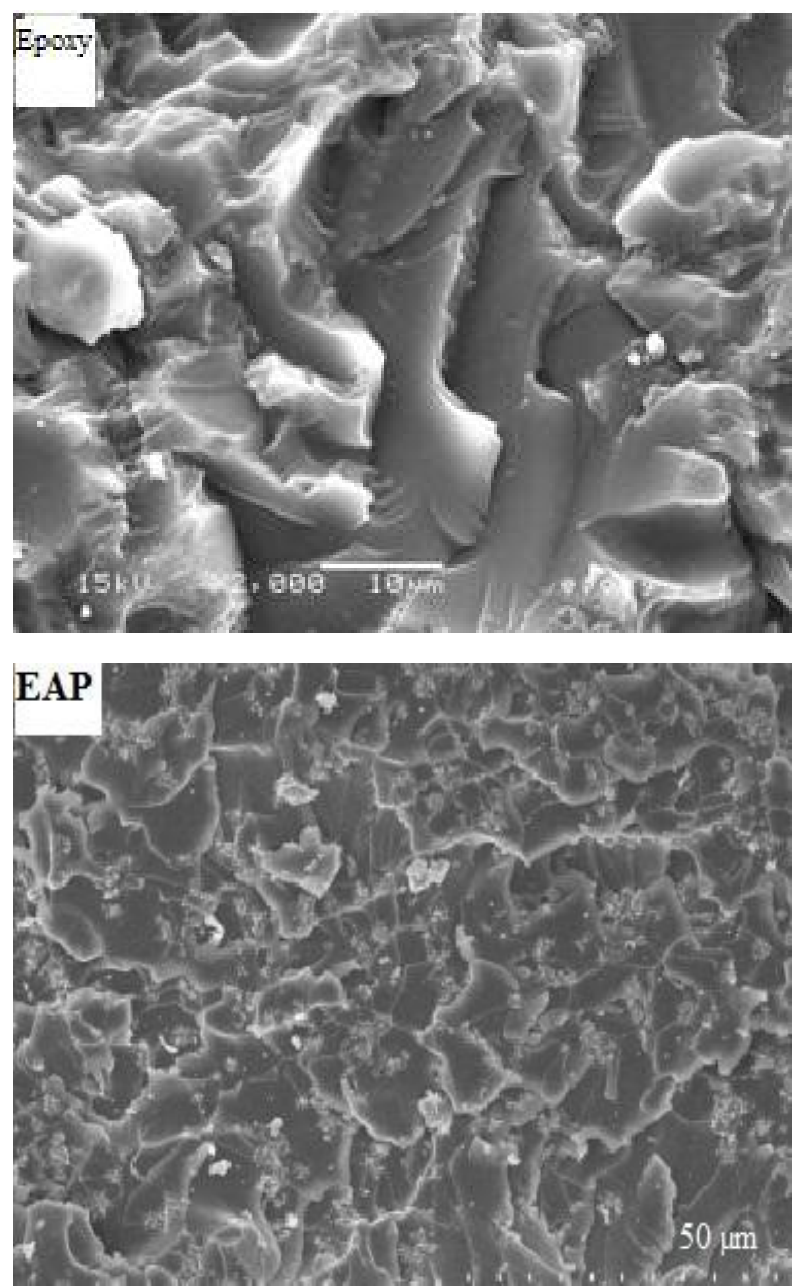

\subsection{Mechanical of Polymer Epoxy Materials}

Blend material between epoxy Epikote (EP) and ELO with ratio $\mathrm{EP} / \mathrm{ELO}=90 / 10$ phr was created. Fig.9. shows that EP/ELO blend material had the slight increasing in the flexural strength were achieved value $88.7 \mathrm{MPa}$. When mixture of two flame retardants $\mathrm{Sb}_{2} \mathrm{O}_{3}$ and chlorinated paraffins with ratio $9 / 11 \mathrm{wt} \%$ was mixed in epoxy, the flexural of epoxy material increased $3 \%$ compared to neat epoxy value $89.26 \mathrm{MPa}$. This is due to the presence of chlorinated paraffins acted as plasticizer thus increased the flexural strength of material. But when mixture epoxy/ $\mathrm{ELO} / \mathrm{Sb}_{2} \mathrm{O}_{3} /$ chlorinated was mixed with each other, the
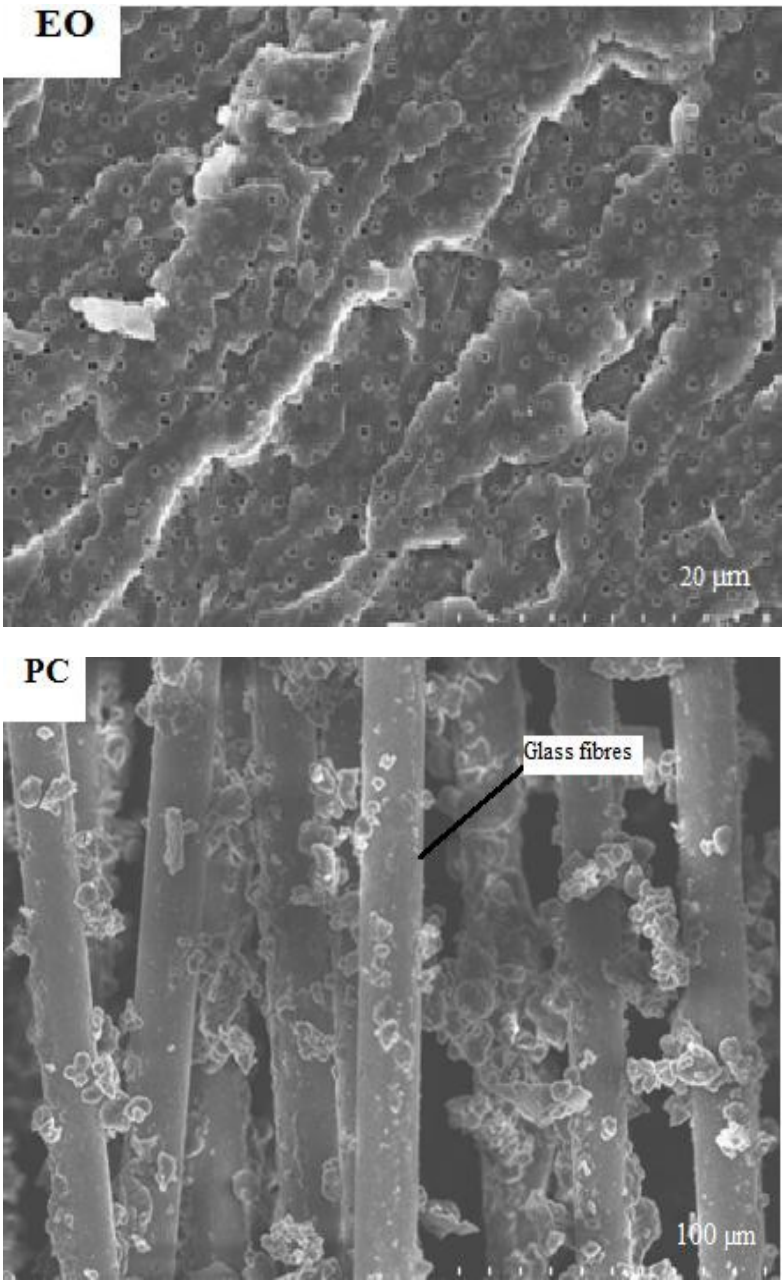

FIG. 7. FE-SEM MICROGRAPHS OF THE SAMPLES: NEAT EPOXY; EPOXY/ EPOXIDIZED LINSEED OIL (EO); EPOXY/ SB, $\mathrm{O}_{3}$ 9PHR /CHLORINATED PARAFFINS 9PHR (EAP); EPOXY/ELO/SB $\mathrm{O}_{3} 9$ PHR /CHLORINATED PARAFFINS $11 P H R / G L A S S$ FIBRES (PC)

Mehran University Research Journal of Engineering \& Technology, Volume 39, No. 1, January, 2020 [p-ISSN: 0254-7821, e-ISSN: 2413-7219] 
flexural strength decreased sharply and achieved value 65.60 MPa. Tensile strength also decreased, especially compressive strength.

From the results of research on the mechanical properties of the base composite material (E 240 / ELO: 90/10 PKL) with the presence of flame retardant (antimony $99 \mathrm{PKL} /$ paraffin $11 \mathrm{PKL}$ ), it is found that the compressive strength of samples decreased significantly compared with samples such as: epoxy E 240; epoxy E 240/ELO; epoxy E 240/oxide antimony $9 \mathrm{PKL} / 11 \mathrm{PKL}$ chlorinated paraphin, that can be explained as follows: The presence of ELO in E 240 epoxy material acts as a plasticizer (as argued in Section 3.1) similar to chlorinated paraffin, therefore the presence of both compounds in the E 240 epoxy polymer material
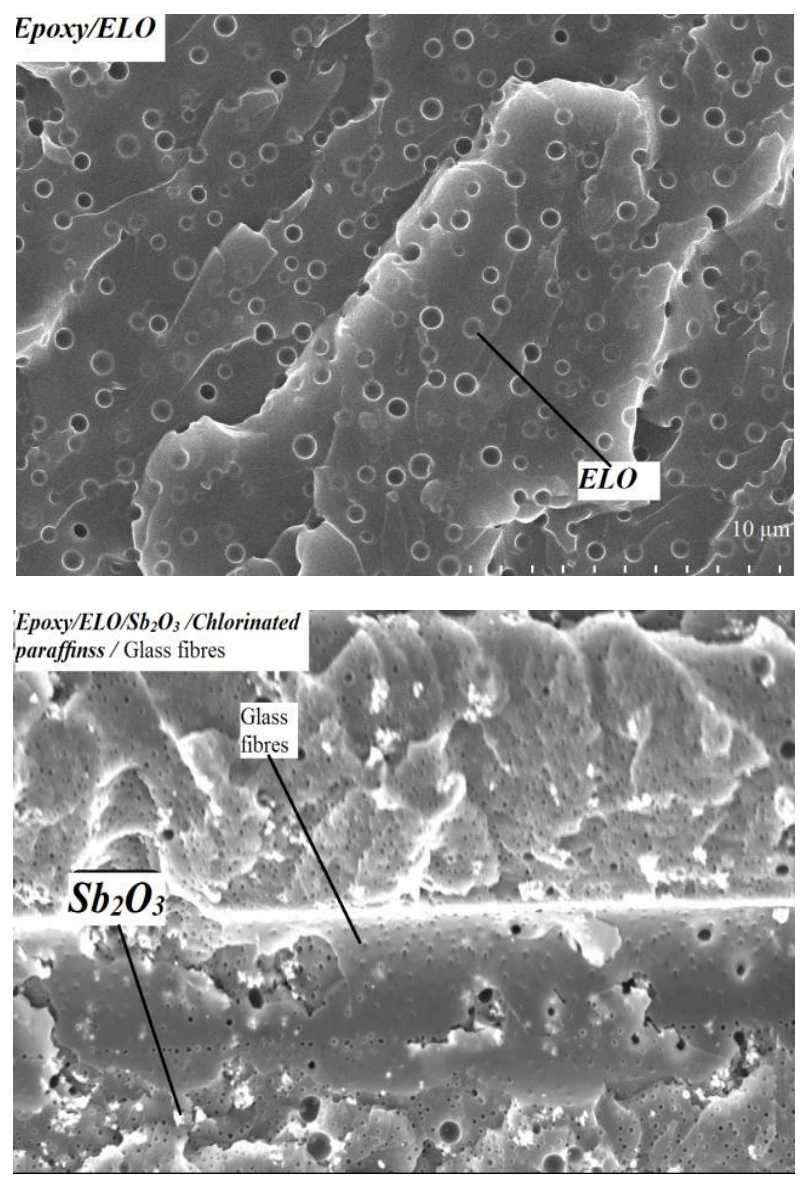

enhances flexibility, reduces the brittleness compared to each compound when used alone.

This is the reason that the impact strength of Izod increases $\left(9.93 \mathrm{KJ} / \mathrm{m}^{2}\right)$, the flexural strength increases (89.40 MPa) compared with E240 epoxy resin background and the remaining materials. Thus, the presence of ELO and chlorinated paraffin increased the ductility of epoxy $240 \mathrm{E}$ polymer significantly. The mechanical properties of epoxy E240/ELO/flame retardant material combinations are shown in Fig.9.

SEM image in Fig.9, shows that the flame retardant $\mathrm{Sb}_{2} \mathrm{O}_{3}$, chlorinated paraffin and epoxidized linseed oil are uniformly
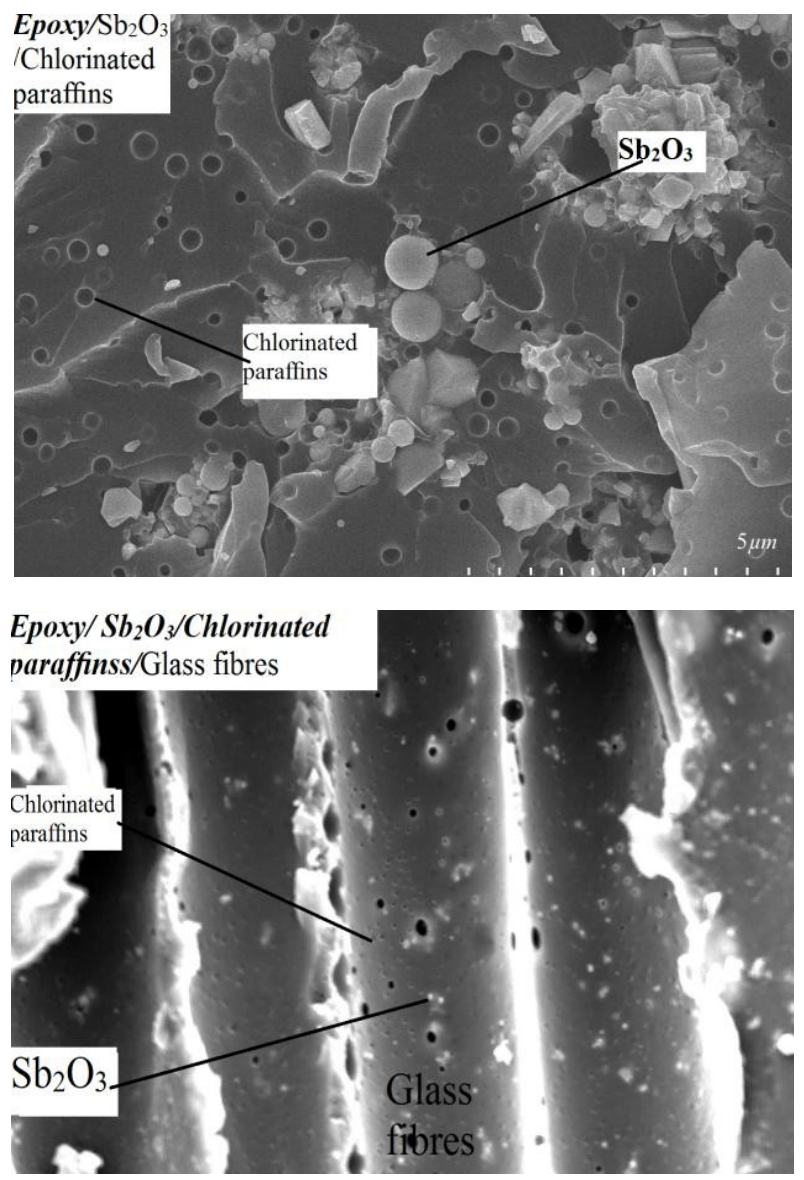

FIG. 8. FE-SEM MICROGRAPHS OF THE SAMPLES: EPOXY/ELO/ $\mathrm{SB}_{2} \mathrm{O}_{3} / C H L O R I N A T E D$ PARAFFINS; EPOXY/SB $\mathrm{O}_{3} /$ CHLORINATED PARAFFINS/ GLASS FIBRES; EPOXY/SB, $\mathrm{O}_{3} /$ CHLORINATED PARAFFINS/ EPOXY/ EPOXIDIZED LINSEED OIL-ELO

Mehran University Research Journal of Engineering \& Technology, Volume 39, No. 1, January, 2020 [p-ISSN: 0254-7821, e-ISSN: 2413-7219] 
distributed in composite materials, chlorinated paraffin and epoxyified linseed oil are distributed as spherical particles of uniform size in the composite, thus it has promoted the effect of improving flexibility, reducing brittleness resulting in flexural strength and impact resistance increased and compression and tensile strength reduced. The adhesion between E 240 epoxy resin and glass fiber plays an important role for the mechanical properties of composite materials and it can be directly related to the roughness of
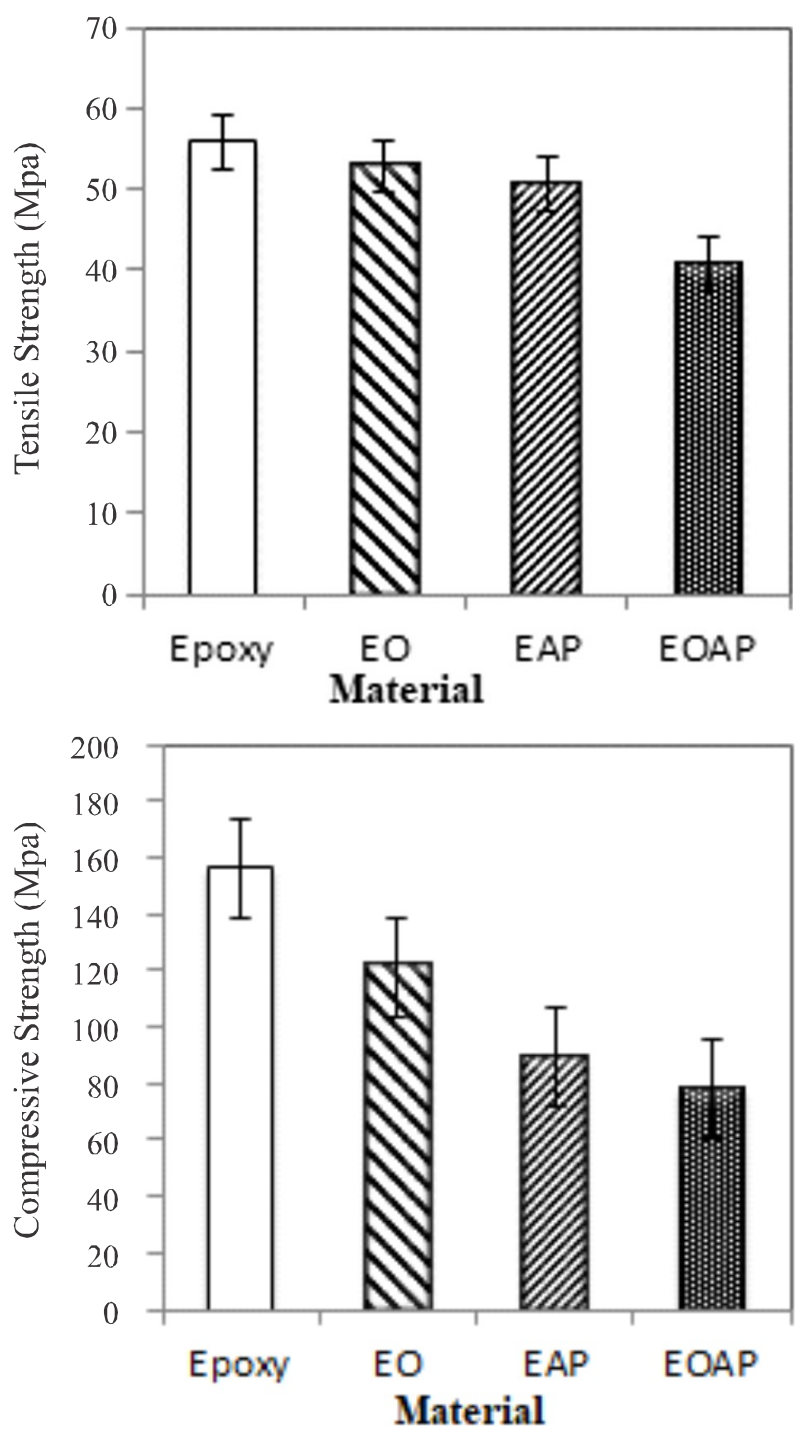

cracks where the formation of cracks occur. The morphological structure fracture surfaces of polyme composite samples after determining the tensile strength, the results are shown in Fig.10.

FE-SEM image in Fig.10 with high resolution, clearly shows that the fractured surface of the E 240 composite epoxy material reinforced with glass cloth and epoxy $\mathrm{E}$ 240/ELO composite material with a flame retardant
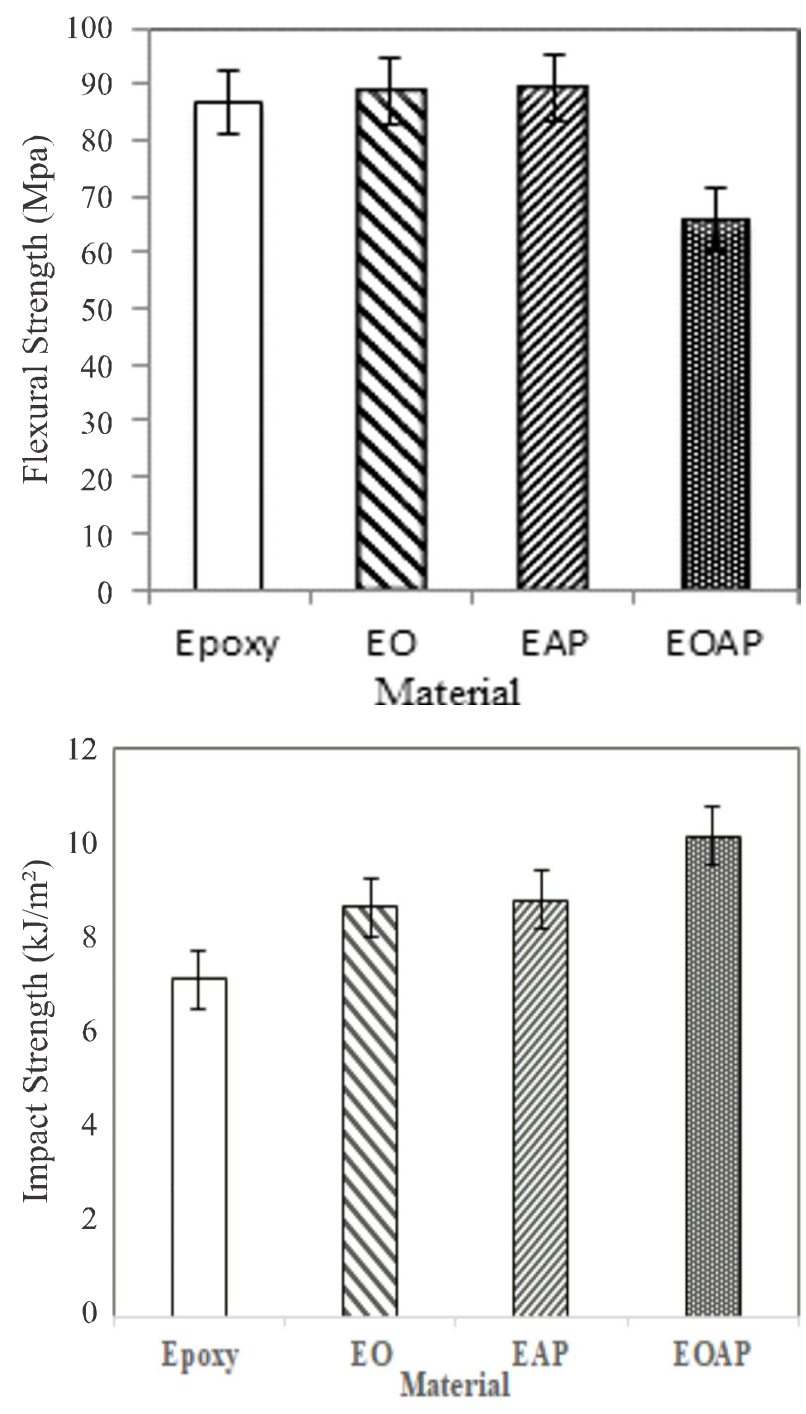

FIG. 9. MECHANICAL STRENGTH OF POLYMER EPOXY MATERIALS: NEAT EPOXY; EPOXY/EPOXIDIZED LINSEED OIL (EO); EPOXY/SB ${ }_{2} \mathrm{O}_{3} 9 \mathrm{PHR} / \mathrm{CHLORINATED} \mathrm{PARAFFINS} \mathrm{11PHR} \mathrm{(EAP);} \mathrm{EPOXY/} \mathrm{EPOXIDIZED} \mathrm{LINSEED} \mathrm{OIL/SB} \mathrm{O}_{3} 9 P H R /$ CHLORINATED PARAFFINS 9PHR (EOAP)

Mehran University Research Journal of Engineering \& Technology, Volume 39, No. 1, January, 2020 [p-ISSN: 0254-7821, e-ISSN: 2413-7219] 
substrate reinforced with glass cloth which was processed by hand pressing method, is relatively smooth, epoxy E 240/ELO/ $\mathrm{Sb}_{2} \mathrm{O}_{3} /$ chlorinated paraffin glass cloth material shows the bond between the fiber and epoxy $240 /$ ELO resin is relatively good, the surface of the slot between the fiber and plastic is partially pulled out of the slot and broken, only the epoxy resin area has smooth fractured surface.

The epoxy E 240 / ELO / $\mathrm{Sb}_{2} \mathrm{O}_{3}$ /chlorinated paraffin/glass cloth material is improved, epoxy E 24/ELO (Fig.10) still adhered to the glass fiber surface after the yarn was removed from the material block and broken when there was an external force effect. Fire retardant additives (antimony oxide, chlorinated paraffin) form a homogeneous mixture with epoxy E240/ELO and they adhere to the glass fiber surface (Fig. 10). Clearly, it shows that there is a good compatibility here and no flaking, hence it has promoted the effect of slowing fire as well as not affecting too much to the decline of mechanical properties .

Thus, the combination of a flame retardant system of antimony and chlorinated paraffin as flame retardant additives for glass-reinforced PC materials based epoxy E240 has been effective and has significantly improved the fire retardation for materials.

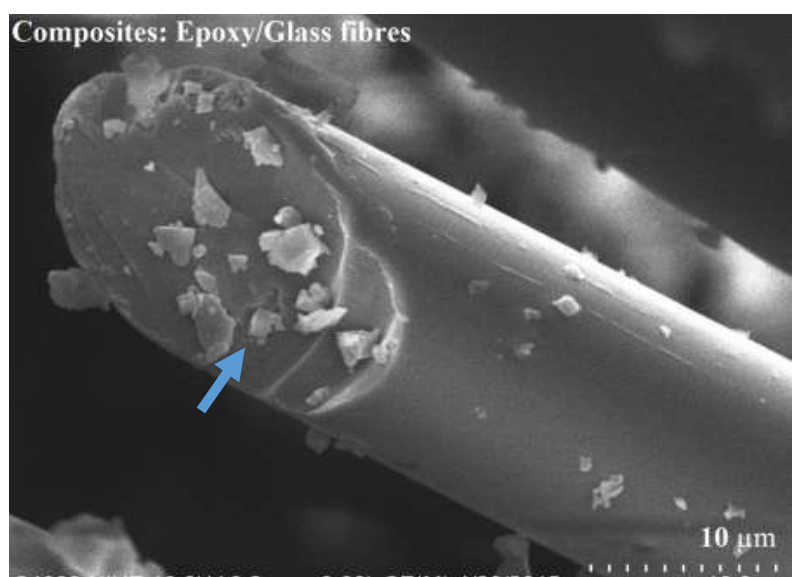

\subsection{Flame Retardancy of Polymer Epoxy Materials}

The fire retardation of epoxy E $240 / \mathrm{ELO} / \mathrm{Sb}_{2} \mathrm{O}_{3} /$ chlorinated paraffin mixture is shown in Fig. 9.

Fig. 11 shows LOI of background material and composite polymer material. These show that the flammability of epoxy resin of mixed ELO increased compared to epoxy background material with no modification. Due to this, ELO acted as a plasticizer and it presence in epoxy background in liquid in curing of epoxy resin increased LOI and achieved value 21.5. When the flame retardants $\mathrm{Sb}_{2} \mathrm{O}_{3}$ and chlorinated paraffins were mixed in EP/ELO, LOI was increased compared to $\mathrm{EP} / \mathrm{Sb}_{2} \mathrm{O}_{3} /$ Chlorinated paraffins and LOI achieved value 23.2 of fire- retardant materials. For composite material, PC3 material (Epoxy/ $\mathrm{ELO} / \mathrm{Sb}_{2} \mathrm{O}_{3} /$ Chlorinated paraffins/glass fibers) achieved LOI 30.3 of self- extingusing materials.

Epoxy E240/ELO/oxide antimony/chlorinated paraffin materials have higher flame retardant properties than other materials, namely, oxygen index of $23.2 \%$, combustion rate of $13.67 \mathrm{~mm} / \mathrm{min}$ and the test on UL94HB equipment with a combustion rate of $20.45 \mathrm{~mm} / \mathrm{min}$. Sturdy structure with less porous holes was observed. The porous holes are the points that cause increased

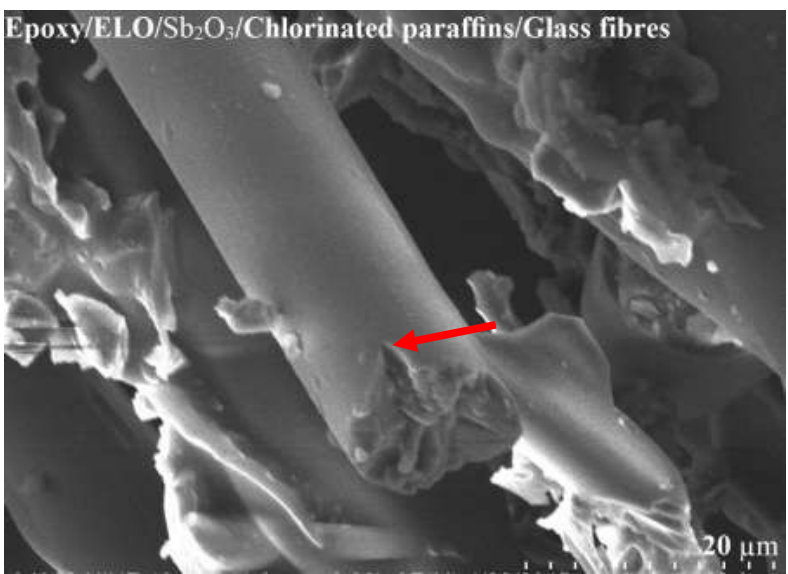

FIG. 10. FE-SEM MICROGRAPHS OF THE SAMPLES: COMPOSITES EPOXY/GLASS FIBRES AND COMPOSITES EPOXY/ELO/CHLORINATED PARAFFINS/GLASS FIBRES

Mehran University Research Journal of Engineering \& Technology, Volume 39, No. 1, January, 2020 [p-ISSN: 0254-7821, e-ISSN: 2413-7219] 
combustion because there are air and porous structures, which also spread the fire faster.

The surface of the material after burning with the oxygen index test using the FE-SEM method was also surveyed. Fig. 12(a) shows that the blank sample of E240 epoxy has a non-intact surface structure that is not intact and on which there are burnt porous areas and cracks (Fig. 12(b)). With composite materials based on epoxy E 240/ELO/oxyt antimony/paraffin chlorinated, there are no cracks on the surface after the fire, smooth surface without porous areas
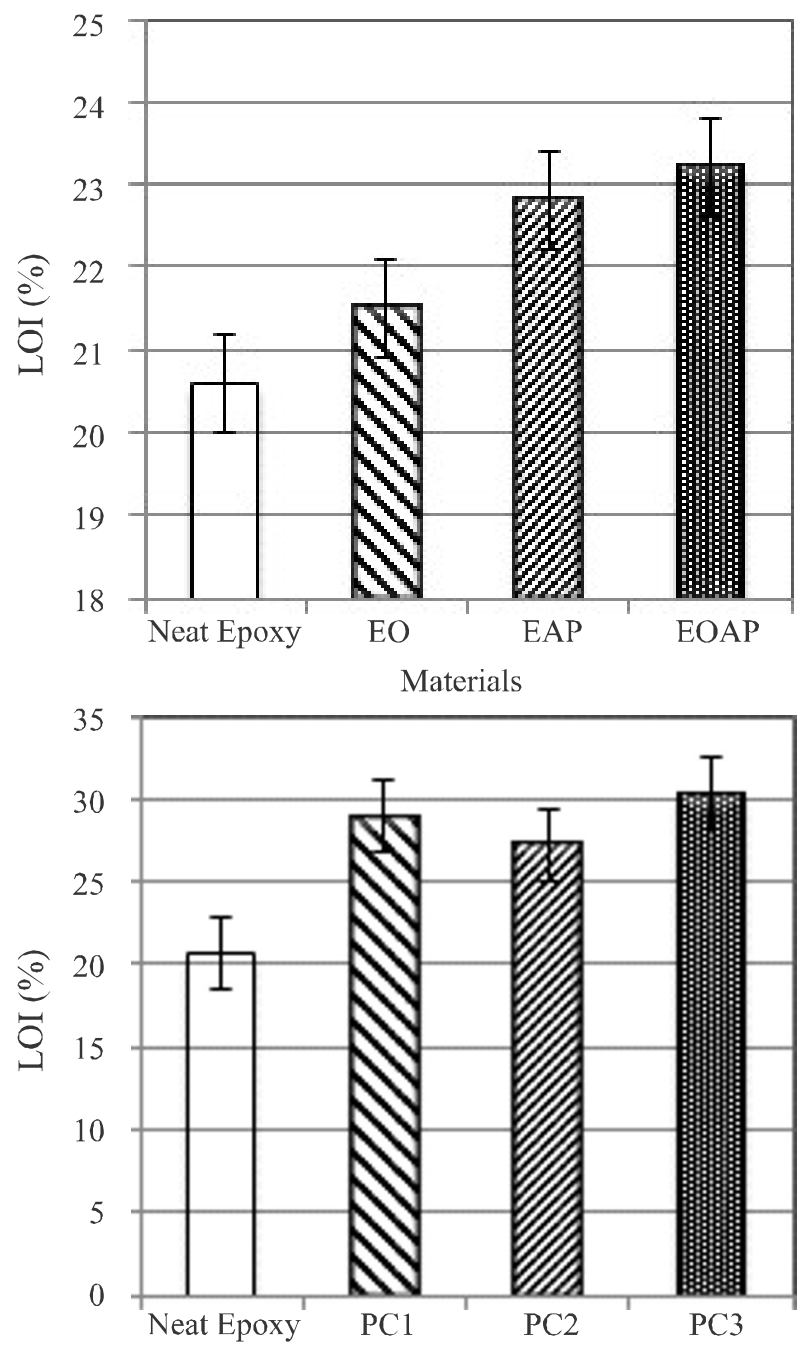

and no visible cracks. Chlorinated paraphin and antimony oxide are produced on E 240 epoxy resin surface, a layer of ash (slag) in the form of solid films, which acts as a barrier to prevent the dispersion of heat and minimizes the loss of volume of volatile substances at epoxy resin surface E240.

When testing the flame retardant properties of glassreinforced PC materials, it was found that only epoxy resin E 240 was burnt with other additives, while the glass cloth remained intact.
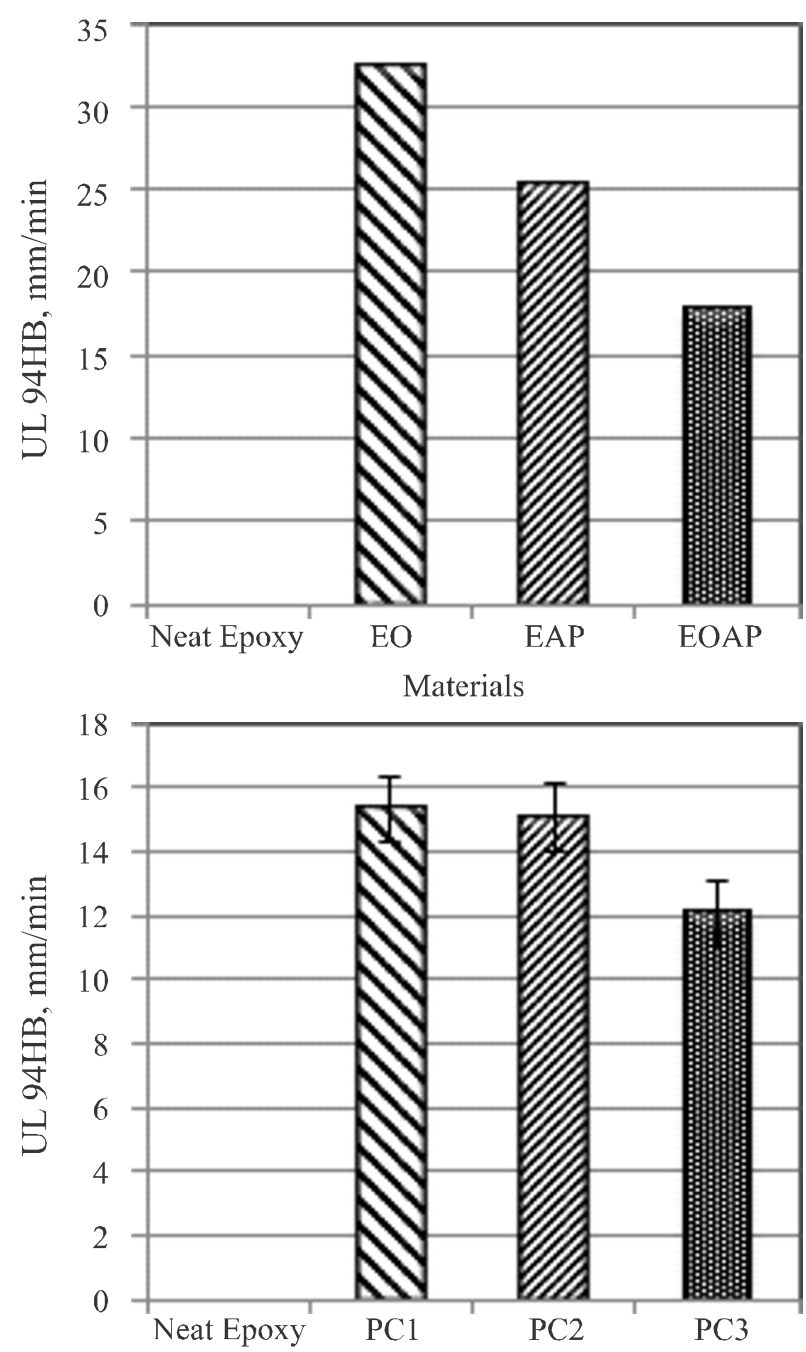

Materials
FIG. 11. MECHANICAL STRENGTH OF POLYMER EPOXY MATERIALS: NEAT EPOXY; EPOXY/ EPOXIDIZED LINSEED OIL (EO); EPOXY/SB $\mathrm{O}_{3} 9$ PHR /CHLORINATED PARAFFINS 11PHR (EAP); EPOXY/EPOXIDIZED LINSEED OIL/SB ${ }_{2} \mathrm{O}_{3} 9 P H R /$ CHLORINATED PARAFFINS 9PHR (EOAP)

Mehran University Research Journal of Engineering \& Technology, Volume 39, No. 1, January, 2020 [p-ISSN: 0254-7821, e-ISSN: 2413-7219] 

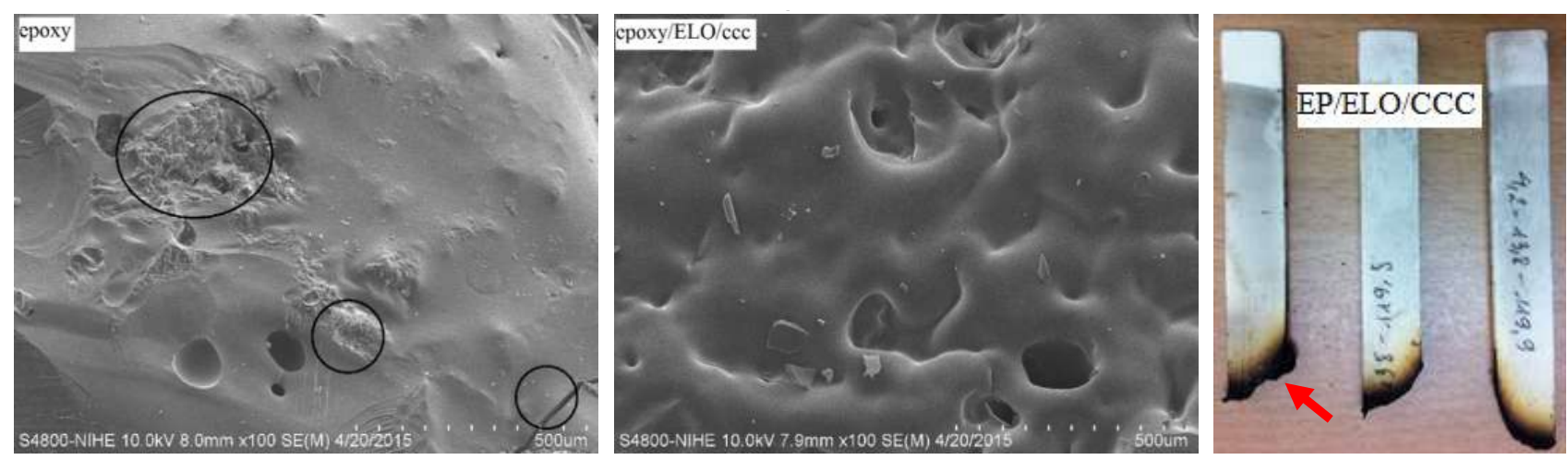

FIG. 12. FE-SEM IMAGES OF THE RESIDUA OF EPOXY/ELO/CCC COMPOSITES (CCC: $\mathrm{SB}_{2} \mathrm{O}_{3} /$ CHLORINATED PARAFFINS)

\section{CONCLUSION}

In this study, we studied to create mixing of epoxy Epikote 240 with ELO and mixture of the flame retardants $\mathrm{Sb}_{2} \mathrm{O}_{3}$ with Chlorinated paraffins. The results showed that, the flammability of composites materials was improved when a part of epoxy resin was replaced by nature resin (ELO). Thus, obtained materials are not only eco-friendly but also increase the flammability with LOI achieved as 30.3. When a fire occurs, the natural plastic materials (ELO) are not only non-toxic with environment but also prevent the fire grow.

Materials E 240/ELO/oxyt antimony/chlorinated paraphin have a high fire resistance: oxygen index $23.2 \%$ and combustion rate $13.67 \mathrm{~mm} / \mathrm{min}$. According to UL 94HB method, the combustion rate reaches $20.45 \mathrm{~mm} / \mathrm{min}$ and the mechanical properties are improved, the flexural strength increases to $89.40 \mathrm{MPa}$ and the impact strength of Izod increases to $9.93 \mathrm{KJ} / \mathrm{m} 2$.

Polymer composite materials based on epoxy E240/ELO resin have a flame retardant system reinforced with "E $600 \mathrm{~g} / \mathrm{m}^{2}$ " rough glass fabric with tensile strength reaching 279.45 Mpa,bending strength of $365.36 \mathrm{MPa}$ and compressive strength of $229.21 \mathrm{MPa}$, Izod impact resistance reaching $158.39 \mathrm{KJ} / \mathrm{m}^{2}$

\section{ACKNOWLEDGEMENT}

The authors wish to thank the Department of Chemical Technology, Hanoi University of Industry for funding this work.

\section{REFERENCES}

[1] O. Fenollar, D. García, L. Sánchez, J. López, R. Balart. "Optimization of the curing conditions of PVC plastisols based on the use of an epoxidized fatty acid ester plasticizer", European Polymer Journal, Volume 45, No. 9, pp. 2674-2684, 2009.

[2] Jianxia Chen, Mark D. Soucek, William J. Simonsickb, Recep W. Celikay, "Synthesis and photopolymerization of norbornyl epoxidized linseed oil", Polymer, Volume 43, pp. 5379-5389, 2009.

[3] Joo Ran Kim, Suraj Sharma, The development and comparison of bio-thermoset plastics from epoxidized plant oils, Industrial Crops and Products, Volume 36(1), pp. $485-499,2012$

[4] D.T. Carter, N. Stansfield, R.J. Mantle, C.M. France, P.A. Smith, An investigation of epoxidised linseed oil as an alternative to PVC in flooring applications, industrial crops and products, Volume 28, pp. 309-319, 2008

[5] Nguyen Tuan Anh, Bach Trong Phuc and Tran Vinh Dieu, "Study the mixing of polymers based on epoxy resin and Epoxidized linseed oil", ISEPD2014 Internation Symposium on Eco-materials Processing and Design, Hanoi, January 12-15, pp. 232-236, 2014.

[6] Vicent Fombuena, Roberto Petrucc, Franco Dominici, Amparo Jordá-Vilaplana,Néstor Montanes and Luigi Torre, "Maleinized Linseed Oil as Epoxy Resin Hardener for Composites with High Bio Content Obtained from Linen Byproducts", Polymers, Volume 11, pp. 1-19, 2019. 
[7]. Tuan Anh Nguyen, Quang Tung Nguyen and Trong Phuc Bach, "Mechanical Properties and Flame Retardancy of Epoxy Resin/Nanoclay/Multiwalled Carbon Nanotube Nanocomposites, Journal of Chemistry, pp. 1-9, 2019.

[8]. Tuan Anh Nguyen, Quang Tung Nguyen, Xuan Canh Nguyen and Van Hoan Nguyen, Study on Fire Resistance Ability and Mechanical Properties of Composites Based on Epikote 240 Epoxy Resin and Thermoelectric Fly Ash: An Ecofriendly Additive, Journal of Chemistry, pp. 1-8, 2019.
[9] Subhan Ali Jogi, Muhammad Moazam Baloch, Ali Dad Chandio, "Iftikhar Ahmed Memon, and Ghulam Sarwar Chandio, Evaluation of Impact Strength of Epoxy Based Hybrid Composites Reinforced with E-Glass/Kevlar 49", Mehran University Research Journal of Engineering \& Technology, Volume 36, No. 4, pp. 1009-1016, 2017.

[10] Hao Tang, ZongMin Zhu, Rui Chen, JunJie Wang, Hong Zhou, Synthesis of DOPO?based pyrazine derivative and its effect on flame retardancy and thermal stability of epoxy resin, Polym Adv Technol, pp. 1-9, 2019. 